\title{
Pre-Induction Cervical Ripening: A Prospective and Comparative Study of Intra-Cervical Foley's Catheter and Prostaglandin E2 Gel
}

\author{
Palvi Banotra $^{1^{*}}$, Adil Rashid ${ }^{2}$ \\ ${ }^{1}$ Department of Health and Medical Education, Jammu and Kashmir \\ ${ }^{2}$ PG Department of Statistics, University of Kashmir, Srinagar \\ ${ }^{*}$ Corresponding Author: Palvi Banotra, Email: palvibntr@gmail.com
}

DOI: https://doi.org/10.52403/ijrr.20220139

\begin{abstract}
Background: Cervical ripening essentially refers to the process of softening the cervix in order to make it prepare for the induction of labor. The success of labor induction depends on the cervical status at the time of induction. There are various methods of cervical ripening; however, in this study we will compare two famous methods of cervical ripening; Foley's cervical catheter and PGE2gel.

Method: This prospective study was conducted at Lala-Ded Hospital, Srinagar from March 2016- September 2017. A total of 70 women fulfilling the defined inclusion criteria were enrolled for this study. They were randomly distributed into 2 groups, Group 1 (Foley's catheter group) and Group 2 (PGE2 gel group) with 35 women included in each group. Patients at term with various indications for induction of labor were included in the study after a comprehensive written consent.
\end{abstract}

Result: The age distribution between the groups was insignificant. We observed that average gestational age was comparable in both the groups with a p-value of 0.526 . However, the average post induction Bishop's score was significantly higher in group 1 compared to group 2 with a p-value of 0.034 .

Conclusion: The present study demonstrated that even though both the methods of cervical ripening are effective but with Foley's intracervical catheter we witnessed a shorter induction delivery interval in comparison to PGE2 gel. Moreover, there was significant improvement in Bishop's score with Foley's catheter. Therefore, we suggest that in developing countries with limited resources Foley catheter is the optimal choice for pre induction cervical ripening in terms of cost effectiveness and attaining the desired results.

Keywords: Cervical ripening, pre labor induction, Foley's cervical catheter, PGE2 gel

\section{INTRODUCTION}

Cervical ripening essentially refers to the process of softening the cervix in order to make it prepare for the induction of labor. This happens by promoting the effacement and dilation as measured by Bishop's score. ${ }^{1}$ Bishops score which is sometimes known as cervix score is a famous pre-labor scoring method to predict whether induction of labor is required or not. It is generally predicted that the patients with a poor Bishop's score $\leq 3$ have unacceptably higher rates of failure of induction. ${ }^{2}$ In cervical ripening process; cervix thins, softens, relaxes and dilates in response to uterine contractions, allowing the cervix to easily pass over the presenting fetal part during labor. Cervical ripening begins prior to the onset of labor contractions and is necessary for cervical dilation and the passage of the fetus. Cervical ripening results from a series of complex biochemical processes that ends with rearrangement and realignment of the collagen molecules. It has been seen that approximately $84 \%$ of women who undergo induction of labor require cervical 
ripening. ${ }^{3,4}$ Generally, the success of labor induction is calculated on the basis of cervical status at the time of induction. The success of labor induction depends on the cervical status at the time of induction. To reduce the induction failure, cervical ripening by exploiting any suitable method methods is the answer. Cervical ripening was commonly performed either mechanically or pharmaceutically. In mechanical method the endogenous prostaglandin production ripens the cervix, mechanical methods were traditional methods of ripening the cervix and induce labor. However, from the last few decades' pharmacological methods of cervical ripening have also been frequently exploited. Presently Foleys catheter balloon have received the maximum attention of medicos as a mechanical choice of the cervical ripening to induce the labor because of low cesarean rate and high likelihood of spontaneous vaginal delivery. ${ }^{5,6}$

\section{MATERIAL AND METHODS}

The study was conducted at LallaDed Hospital, Srinagar. A total of 70 women fulfilling the inclusion criteria were enrolled for this study. They were randomly distributed into 2 groups, Group 1 (Foley's catheter group) and Group 2 (PGE2 gel group) with 35 women included in each group. The study population $(n=70)$ was a mixture of high and low risk population. Patients at term with various indications for induction of labor were included in the study after a written, valid consent.

\section{Inclusion criteria}

(a) Primigravida

(b) $\geq 37$ weeks of gestation

(c) Singleton pregnancy

(d) Cephalic presentation

(e) Bishops score $\leq 3$

(f) Intact membranes

\section{Exclusion criteria}

(a) Multiple pregnancy

(b) Mal-presentation

(c) Absent membranes (d) $\mathrm{APH}$

(e) Medical disease e.g., heart disease, renal disease

After proper counseling, written consent was taken from each patient. In Group 1, a16 F Foley's catheter was inserted under aseptic conditions into cervical canal and balloon was inflated with $50 \mathrm{ml}$ of water. The catheter was left undisturbed until spontaneous expulsion or no longer than 12 hours. Bishop's score was assessed if catheter is expelled spontaneously and if not expelled in 12 hours, catheter was adjusted to maintain continuous traction. Bishop's score was again assessed after 12 hours and cases were taken as a failure if patient does not go into active labor within $24 \mathrm{hrs}$. Women in (group 2) received PGE2 gel intra-cervically. Before giving next dose, Bishop's scoring was done and if required doses were repeated at 6-8 hours interval to a maximum of 3 doses. The primary outcome was change in Bishop's score. The secondary outcomes were induction delivery interval, need for augmentation, mode of delivery and neonatal outcome

Statistical Methods: The recorded data was compiled and entered in a spreadsheet (Microsoft Excel) and then exported to data editor of SPSS Version 20.0 (SPSS Inc., Chicago, Illinois, USA). Continuous variables were expressed as Mean \pm SD and categorical variables were summarized as frequencies and percentages. Student's independent t-test or Mann-Whitney U-test, whichever feasible, was employed for comparing continuous variables. Chi-square test or Fisher's exact test, whichever appropriate, was applied for comparing categorical variables. For intra-group analysis of data, paired t-test was applied. A P-value of less than 0.05 was considered statistically significant. All P-values were two tailed.

The average age of patients in group 1 and group 2 was respectively observed as $(23.4 \pm 3.09) \quad$ years and $(22.9 \pm 2.78)$ respectively. Majority of patients were from 
Palvi Banotra et.al. Pre-induction cervical ripening: a prospective and comparative study of intra-cervical Foley's catheter and prostaglandin E2 gel

(20-24) year age group in both the groups. Evidently, the age distribution between the groups was insignificant. We observed that average gestational age was comparable in both the groups with a p-value of 0.526 .

Table 1: Age distribution of study patients in two groups

\begin{tabular}{|c|c|c|c|c|c|}
\hline \multirow[t]{2}{*}{ Age (Years) } & \multicolumn{2}{|c|}{ Group 1} & \multicolumn{2}{|c|}{ Group 2} & \multirow[t]{2}{*}{ P-value } \\
\hline & No. & \%age & No. & \%age & \\
\hline$\leq 20$ & 2 & 5.7 & 3 & 8.6 & \multirow[t]{6}{*}{0.479} \\
\hline $20-24$ & 23 & 65.7 & 21 & 60.0 & \\
\hline $25-29$ & 10 & 28.6 & 11 & 31.4 & \\
\hline $30-34$ & 2 & 5.7 & 3 & 8.6 & \\
\hline Total & 35 & 100 & 35 & 100 & \\
\hline Mean \pm SD & \multicolumn{2}{|c|}{$23.4 \pm 3.09$} & \multicolumn{2}{|c|}{$22.9 \pm 2.78$} & \\
\hline
\end{tabular}

Group 1 (Foley's catheter); Group 2 (PGE2 Gel)

Table 2: Bishop score in two groups before and after induction

\begin{tabular}{|c|c|c|c|c|c|c|}
\hline \multirow[t]{2}{*}{ Bishop score } & \multicolumn{2}{|c|}{ Pre-induction } & \multicolumn{2}{|c|}{ Post-induction } & \multirow[t]{2}{*}{ Difference } & \multirow[t]{2}{*}{ P-value } \\
\hline & Mean & SD & Mean & SD & & \\
\hline Group 1 & 1.67 & 0.734 & 8.31 & 2.135 & 6.64 & $<0.001 *$ \\
\hline Group 2 & 1.53 & 0.639 & 7.28 & 1.816 & 5.75 & $<0.001 *$ \\
\hline P-value & \multicolumn{2}{|c|}{0.398} & \multicolumn{2}{|c|}{$0.034 *$} & \multicolumn{2}{|c|}{$0.041 *$} \\
\hline
\end{tabular}

We observe that pre-induction average Bishop score between the groups was comparable. However, mean post induction Bishops score between the groups was statistically significant with a p-value of 0.034*. Evidently, a high significance in pre-post induction Bishops score was observed in both the groups with a p-value of $(<0.0001 *)$

Table 3: Need for augmentation in two groups

\begin{tabular}{|c|c|c|c|c|c|}
\hline \multirow{2}{*}{$\begin{array}{c}\text { Need for } \\
\text { augmentation }\end{array}$} & \multicolumn{2}{|c|}{ Group 1 } & \multicolumn{2}{|c|}{ Group 2 } & P-value \\
\cline { 2 - 5 } & No. & \%age & No. & \%age & \\
\hline Spontaneous & 8 & 22.9 & 11 & 31.4 & 0.841 \\
\hline ARM & 4 & 11.4 & 3 & 8.6 & \\
\hline Oxytocin & 13 & 37.1 & 13 & 37.1 & \\
\hline ARM+ Oxytocin & 10 & 28.6 & 8 & 22.9 & \\
\hline Total & $\mathbf{3 5}$ & $\mathbf{1 0 0}$ & $\mathbf{3 5}$ & $\mathbf{1 0 0}$ & \\
\hline
\end{tabular}

Requirement of augmentation in both the groups was assessed and it was found that majority of patients $(37.1 \%)$ in each group required oxytocin augmentation. Spontaneous augmentation was observed in (22.9\%) patients in group 1 and $(31.4 \%)$ in group 2. However, there was an insignificant difference between the groups with respect to requirement of augmentation.

Table 4: Mode of delivery in two groups
\begin{tabular}{|c|c|c|c|c|c|}
\hline Mode of & \multicolumn{2}{|c|}{ Group 1 } & \multicolumn{2}{c|}{ Group 2 } & \multirow{2}{*}{ P-value } \\
\cline { 2 - 5 } delivery & No. & \% age & No. & \% age & \\
\hline Vaginal & 29 & 82.9 & 27 & 77.1 & \multirow{2}{*}{0.781} \\
\hline LSCS & 5 & 14.3 & 6 & 17.1 & \\
\hline Forceps & 1 & 2.9 & 2 & 5.7 & \\
\hline Total & $\mathbf{3 5}$ & $\mathbf{1 0 0}$ & $\mathbf{3 5}$ & $\mathbf{1 0 0}$ & \\
\hline
\end{tabular}

We observed that around (83\%) patients in group 1 delivered vaginally in comparison to $(77.1 \%$ ) in group 2 . Rest of the patients in both the groups had either LSCS or forceps mode of delivery.
However, an insignificant difference was observed between the groups with respect to mode of delivery with a p-value of 0.781

Table 5: Comparison based on induction delivery interval in two groups

\begin{tabular}{l} 
two groups \\
\begin{tabular}{|c|c|c|c|c|c|}
\hline Group & $\mathbf{N}$ & Mean & SD & 95\% CI & P-value \\
\hline Group 1 & 35 & 11.9 & 3.89 & $9.13-13.75$ & \multirow{2}{*}{$<0.001 *$} \\
\hline Group 2 & 35 & 15.3 & 4.71 & $13.94-16.82$ & \\
\hline
\end{tabular} \\
\hline
\end{tabular}

*Statistically Significant Difference $(\mathbf{P}$-value $<0.05)$

We evaluated patients induction delivery interval in two groups and observed that its significantly higher in group 2 compared to group 1 with a p-value of $<0.0001 *$

Table 6: Comparison based on neonatal outcome (apgar score) in two groups

\begin{tabular}{|c|c|c|c|c|c|c|}
\hline \multicolumn{2}{|c|}{ Apgar Score } & \multicolumn{2}{|c|}{ Group 1 } & \multicolumn{2}{c|}{ Group 2 } & \multirow{2}{*}{ P-value } \\
\cline { 3 - 7 } \multicolumn{2}{|c|}{} & No. & \% age & No. & \% age & \\
\hline \multirow{2}{*}{1 Min } & $<7$ & 3 & 8.6 & 2 & 5.7 & \multirow{2}{*}{0.643} \\
\cline { 2 - 6 } & $\geq 7$ & 32 & 91.4 & 33 & 94.3 & \\
\hline \multirow{2}{*}{5 Min } & $<7$ & 0 & 0.0 & 2 & 5.7 & \multirow{2}{*}{1.000} \\
\cline { 2 - 6 } & $\geq 7$ & 35 & 100 & 34 & 97.1 & \\
\hline
\end{tabular}

APGAR score at $1 \mathrm{~min}$ and $5 \mathrm{~min}$ was analyzed and it was found that both the groups have a comparable (insignificant) difference in APGAR score between the groups

Table 7: Incidence of side effects in two groups

\begin{tabular}{|c|c|c|c|c|c|}
\hline \multirow{2}{*}{ Side effects } & \multicolumn{2}{|c|}{ Group 1 } & \multicolumn{2}{c|}{ Group 2 } & \multirow{2}{*}{ P-value } \\
\cline { 2 - 5 } & No. & \% age & No. & \%age & \\
\hline Yes & 1 & 2.9 & 2 & 5.7 & \multirow{2}{*}{0.556} \\
\hline No & 34 & 97.1 & 33 & 94.3 & \\
\hline Total & $\mathbf{3 5}$ & $\mathbf{1 0 0}$ & $\mathbf{3 5}$ & $\mathbf{1 0 0}$ & \\
\hline
\end{tabular}

The incidence of side effects in group 1 and group 2 was assessed, and an insignificant difference between the groups was observed with a p-value of 0.556 


\section{DISCUSSION}

In the present study we observed that the average age of patients in group 1 and group 2 was $(23.4 \pm 3.09)$ years and $(22.9 \pm 2.78)$ respectively. Majority of patients were from (20-24) year age group in both the groups. Evidently, the age distribution between the groups was insignificant. In a likewise study by Murmu et al, authors obtained the similar results on age distribution of patients placed in likewise two groups, the mean age of patients for group 1 and group 2 patients was respectively reported $22.12 \pm 2.78$ years and 22.72 \pm 2.73 year, which was comparable. ${ }^{7} \mathrm{We}$ observed that average gestational age was comparable between the groups with a p-value of 0.526 , which is in consonance with the results reported by Dhamavijav et al and Murmu et al. ${ }^{7,8} \mathrm{We}$ observed that pre-induction average Bishop's score between the groups was comparable. However, mean post induction Bishops score corresponding to group 1 was significantly higher (8.31) compared to (7.28) in group 2. Evidently, a high significance in pre-post induction Bishops score was observed in both the groups with a p-value of $(<0.0001 *)$. Much similar to our observations several authors have reported almost the same results, for instance; Murmu et al reported an insignificant pre- induction Bishop's score, however, post induction bishop's score was significant with a p-value of 0.0094 which is much similar to our observation, likewise to our results they also observed that mean change in Bishop's score in Foley's group (group 1) was $6.45 \pm 1.06$ and that in PGE2 gel group (group 2) was $5.85 \pm 1.35$ and this difference was statistically significant $(\mathrm{p}=0.004) .{ }^{7}$ Similarly, Sciscione et al and Onge et al also reported significantly higher average of Bishop's score and mean change Bishop's score in group 1 compared to group 2. ${ }^{9,10} \mathrm{We}$ evaluated patients induction delivery interval in two groups and observed that its significantly higher in group 2 compared to group 1 with a p-value of $<0.0001 *$. Contrary to this, Deshmukh et al and Revathi et al have reported higher induction delivery interval in group 1 rather than in group 2. ${ }^{11,12}$ However, contemporarily to our results numerous authors have reported likewise results; for instance, Murmu et al, Dalui et al and Schreyer etr al have reported significantly lower induction delivery interval of Foley's catheter (group 1) compared to PGE2 gel (group2). ${ }^{7,13}$ In the present study we evaluated the requirement of augmentation in both the groups and it was found that majority of patients (37.1\%) in each group required oxytocin augmentation. Spontaneous augmentation was observed in $(22.9 \%)$ patients in group 1 and $(31.4 \%)$ in group 2. We found an insignificant difference between the groups with respect to oxytocin augmentation. Unlike to this, Taani et al have reported higher requirement of oxytocin in patients whose cervical ripening was performed via Foley's catheter compared to PGE2 gel. ${ }^{14}$ However, likewise to our results, Murmu et al have reported comparable requirement of oxytocin in both the groups. ${ }^{7}$ We observed that around $(83 \%)$ patients in group 1 delivered vaginally in comparison to $(77.1 \%)$ in group 2 . Rest of the patients in both the groups had either LSCS or forceps mode of delivery. However, an insignificant difference was observed between the groups with respect to mode of delivery with a p-value of 0.781 , these results are comparable with Murmu et al. ${ }^{7}$ The present study revealed that both these methods are producing comparable neonatal outcome based on (APGAR score), and both these induction methods are safer for them. Ghezzi et al and Murmu et al have also demonstrated an insignificant neonatal outcome in both these methods of cervical ripening. ${ }^{7,15}$ Ultimately the two methods were evaluated on the basis of side effects, the incidence of side effects in group 1 and group 2 was assessed, and an insignificant difference between the groups was observed with a p-value of 0.556 . However, unlike to this, several authors have reported higher incidence of side effects like; vomiting, 
diarrhea and fever in PGE2 gel (group 2) compared to group $1 .^{7,16}$

\section{CONCLUSION}

The present study demonstrated that even though both the methods of cervical ripening are effective but with Foley's intracervical catheter we witnessed a shorter induction delivery interval in comparison to PGE2 gel. Moreover, there was significant improvement in Bishop's score with Foley's catheter. Therefore, we suggest that in developing countries with limited resources Foley catheter is the optimal choice for pre induction cervical ripening in terms of cost effectiveness and attaining the desired results.

\section{Acknowledgement: None}

\section{Conflict of Interest: None}

\section{Source of Funding: None}

\section{Ethical Approval: Approved}

\section{REFERENCES}

1. National Institute for Clinical Excellence. Clinical guidelines for induction of labour, Appendix-E. London: NICE; 2001.

2. St. Onge RD, Conners GT. Preinduction cervical ripening: a comparison of intracervical PGE2 gel vs. the Foley catheter. Am J Obstet Gynecol. 1995;172: 687-90.

3. Bernardes TP, Broekhuijsen K, Koopmans CM, Boers KE, van Wyk L, Tajik P, et al. Caesarean section rates and adverse neonatal outcomes after induction of labour versus expectant management in women with an unripe cervix: a secondary analysis of the HYPITAT and DIGITAT trials. BJOG 2016;123:1501-8. doi: 10.1111/1471-0528.14028

4. Bartha JL, Romero-Carmona R, MartinezDel-Fresno P, Comino-Delgado R. Bishop score and transvaginal ultrasound for preinduction cervical assessment: a randomized clinical trial. Ultrasound Obstet Gynecol 2005;25:155-9. doi: 10.1002/uog. 1813
5. Gu N, Ru T, Wang Z, Dai Y, Zheng M, $\mathrm{Xu} \mathrm{B}$, et al. Foley catheter for induction of labor at term: an open-label, randomized controlled trial. PloS one. 2015;10(8):e 0136856.

6. James C, Peedicayil A, Seshadri L. Use of the Foley catheter as a cervical ripening agent prior to induction of labor. Int $\mathbf{J}$ Gynecol Obstet. 1994;47(3):229-32

7. Murmu S, Dwivedi C. A comparative study of intracervical Foley's catheter and intracervical PGE2 gel for pre-induction cervical ripening. Int J Reprod Contracept Obstet Gynecol 2018;7:3122-5.

8. Dharmavijaya MN, Umashankar KM, Kavitha G, Nagpure AG, Comparative study of intra-cervical Foley's catheter and PGE2 gel for pre-induction cervical ripening. Int $\mathrm{J}$ Basic and applied Med Sci. 2013;3(1): 247-53.

9. Sciscione AC, McCullough H, Manley JS, Shlossman PA, Pollock M, Colmorgen GH. A prospective, randomized comparison of Foley catheter insertion versus intracervical prostaglandin E2 gel for preinduction cervical ripening. Am $\mathbf{J}$ Obstetr Gynecol. 1999;180(1):55-9.

10. Onge RD, Connors GT. Preinduction cervical ripening: a comparison of intracervical prostaglandin E2 gel versus the Foley catheter. Am J Obstetr Gynecol. 1995;172(2):687-90.

11. Deshmukh VL, Yelikar KA, Deshmukh AB. Comparative Study of Intra-cervical Foley's Catheter and PGE 2 Gel for Preinduction Ripening (Cervical). J Obstetr Gynecol India. 2011;61(4):418.

12. Revathi V, Archana I. A Comparative study of efficacy of intracervical prostaglandin E2 gel and intracervical Foley's catheter for pre-induction cervical ripening. J Dental Med Sci (IOSR-JDMS). 2015;14(4):42-6.

13. Dalui R, Suri V, Ray P, Gupta I. Comparison of extraamniotic Foley catheter and intracervical prostaglandin $\mathrm{E}$ 2 gel for preinduction cervical ripening. Acta Obstetr Gynecol Scandinav. 2005; 84(4):362-7.

14. Al-Taani MI. Comparison of prostaglandin E. Eastern Mediterranean Health J. 2004; 10(4/5):547. 
Palvi Banotra et.al. Pre-induction cervical ripening: a prospective and comparative study of intra-cervical Foley's catheter and prostaglandin E2 gel

15. Ghezzi F, Massimo F, Raio L, Di Naro E, Balestreri D, Bolis P. Extra-amniotic Foley catheter and prostaglandin E2 gel for cervical ripening at term gestation. Eur J Obstetr Gynecol Reprod Biol. 2001; 97(2): 183-7

16. Penaguluru R, Yaragani P, Padmaja P. comparative study of intra-cervical Foley's catheter and intra-cervical PGE2 gel for pre-induction ripening of cervix. Int J Contemp Med Res. 2016;3(2):410-3.
How to cite this article: Banotra P, Rashid A. Pre-induction cervical ripening: a prospective and comparative study of intra-cervical Foley's catheter and prostaglandin E2 gel. International Journal of Research and Review. 2022; 9(1): 328-333. DOI: https:// doi.org/10.52403/ijrr.20220139

$* * * * * *$ 